\title{
Modification of 6,6-Type Polyamide Containing Both $\gamma$-Lactone Ring and Hydrophilic Groups
}

\author{
Takao Kimura, ${ }^{*}$ Kazunobu TanJI, ${ }^{\dagger}$ Ryuichiro SASAKI, ${ }^{\dagger \dagger}$ \\ Daisuke SATo, ${ }^{\dagger \dagger}$ and Masahiro MinaBE \\ Department of Applied Chemistry, Faculty of Engineering, Utsunomiya University, \\ Ishii-machi, Utsunomiya 321, Japan
}

(Received August 13, 1992)

\begin{abstract}
The interfacial polycondensation of $\left(2 R^{*}, 4 S^{*}\right)$-4-chloroformyl-2-chloroformylmethyl-2,4-dimethyl-4-butanolide (BC) with 1,6-hexanediamine (HDA) gives an unique 6,6-type polyamide (PA-6L) with partial hydrolytic cleavage of the lactone moiety. PA-6L containing at random both $\gamma$-lactone ring and hydrophilic groups such as carboxyl and hydroxyl groups was modified by the following three methods: 1) ring-opening of the lactone groups in PA-6L by chemical treatment, 2) incorporation of nylon-66 (PA-66) sequence into PA-6L chain by interfacial copolycondensation, and 3) crosslinking of PA-6L with methylene bis(4-phenylisocyanate) (MDI). The ring-opening ratio of PA- $6 \mathrm{~L}$ increased by treating with either acids or alkalis, whereas $[\eta]$ decreased. In particular, the carboxylato-containing PA-6L prepared by the treatment with potassium hydroxide was highly soluble in water. In the interfacial copolycondensation of acid dichlorides, $\mathrm{BC}$ and adipoyl chloride (AC), with HDA, a methanol-soluble copolyamide PA-6L/66 was prepared at an $[\mathrm{AC}] /([\mathrm{BC}]+[\mathrm{AC}])$ mole fraction of $c a$. 0.25 . PA-6L crosslinked with MDI had a decomposition point of $303^{\circ} \mathrm{C}$ and showed a lower thermostability beyond $280^{\circ} \mathrm{C}$ than the original one.
\end{abstract}

KEY WORDS Modification / Hydrophilic 6,6-Type Polyamide / Lactone Ring-Opening / Water-Soluble Nylon / Copolycondensation / Crosslinking / Methylene Bis(4-phenylisocyanate) / Thermostability /

In a previous paper, ${ }^{1}$ we reported the preparation of bifunctional lactone monomer, namely $\left(2 R^{*}, 4 S^{*}\right)$-4-chloroformyl-2-chloroformylmethyl-2,4-dimethyl-4-butanolide (BC) by the chemical transformation of $t$-butyl methacrylate (TBMA) cyclic dimer, obtained from the telomerization of TBMA using bromotrichloromethane as a telogen. The interfacial polycondensation of $\mathrm{BC}$ with 1,6hexanediamine (HDA) was accompanied by a partial hydrolytic cleavage of the $\gamma$-lactone ring, and gave unique 6,6-type polyamide (PA-6L) containing both $\gamma$-lactone ring and hydrophilic groups such as carboxyl and hydroxyl groups. PA-6L was highly soluble in methanol, and a transparent and flexible film was prepared from the methanol solution by a casting technique.

In the preceding paper, ${ }^{2}$ we reported the preparation of amphiphilic graft copolymers

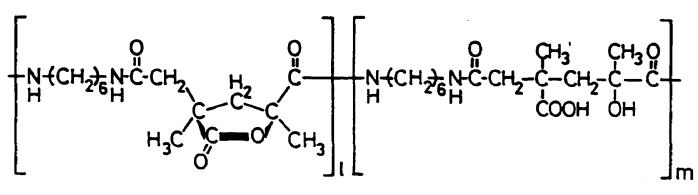

(PA-6L)

* To whom all correspondence should be addressed.

† Present address: Nippon Mectron Ltd., 831-2, Isohara-machi, Kitaibaraki 319-15, Japan.

${ }^{\dagger \dagger}$ Present address: Tokimec Inc., 333-4, Higashi-machi, Yaita 329-21, Japan.

${ }^{+\dagger}$ Present address: Hitachi Cable, Ltd., 4-10-1, Kawajiri-machi, Hitachi 319-14, Japan. 
consisting of hydrophilic PA-6L as a backbone and hydrophobic oligostyrene as a branch by coupling between the PA-6L and chloroformyl-semitelechelic oligostyrene.

This paper deals with modification of PA$6 \mathrm{~L}$ by the following three methods: 1) ringopening of the lactone groups in PA-6L by chemical treatment, 2) incorporation of nylon-66 (PA-66) sequence into PA-6L chain by interfacial copolycondensation, and 3) crosslinking of PA-6L with methylene bis(4phenylisocyanate) (MDI). The structure and characterization of modified PA-6L are discussed and compared with those of an untreated sample.

\section{EXPERIMENTAL}

\section{Materials}

The original PA-6L was prepared by the interfacial polycondensation of $\mathrm{BC}$ with HDA as described in the previous paper. ${ }^{1}$ Adipoyl chloride (AC) was prepared by the chlorination of adipic acid with thionyl chloride. Commercial MDI was distilled in vacuo before use. Commercial $N, N$-dimethylacetamide (DMAc) was dried over calcium hydride and distilled before use. Other reagents and solvents were commercially obtained and used without further purification.

\section{Characterization of Samples}

IR spectra were measured with a JASCO IR REPORT-100 spectrophotometer. The ringopening ratio, $m /(l+m)$, of PA-6L was determined from absorbance $(A)$ on IR spectrum (film): $A_{1700} /\left(A_{1780}+A_{1700}\right) \times 100 \%$ : where, $A_{1700}$ : absorbance at $1700 \mathrm{~cm}^{-1}, A_{1780}:$ absorbance at $1780 \mathrm{~cm}^{-1}$. The water content of PA-6L was calculated as follows: ( $W_{\text {wet }}-$ $\left.W_{\text {dry }}\right) / W_{\text {dry }} \times 100 \%$ : where, $W_{\text {wet }}$ : weight of swollen PA-6L at $95 \%$ relative humidity for $24 \mathrm{~h}, W_{\mathrm{dry}}$ : weight of dry PA-6L. The intrinsic viscosity $[\eta]$ of PA-6L was measured with a Ubbelohde viscometer. The viscosity-average molecular weight $\left(\bar{M}_{v}\right)$ of PA-6L was evaluated qualitatively by Elias's equation for PA- $66 .^{3}$ DSC curves of polymers were recorded on a SEIKO DSC-220C at a heating rate of $20^{\circ} \mathrm{C} \mathrm{min}^{-1}$ under a nitrogen atmosphere. TG curves of polymers were measured with a SEIKO TG/DTA-220 under the same conditions as measurements of the DSC curves.

\section{Chemical Treatment of PA-6L with Acids and Alkalis}

To a solution of PA-6L $(0.2 \mathrm{~g}, 2.13 \times$ $\left.10^{-2} \mathrm{mmol}\right)$ in methanol $(15 \mathrm{ml})$, a treatment agent $(5 \mathrm{ml})$ was added at r.t. without stirring, and the mixed solution was immediately evaporated to dryness using a rotary vacuum evaporator. In the case of potassium hydroxide $(\mathrm{KOH})$-treatment, the residue was passed through a column packed with Sephadex G-10 (size, i.d. $22 \mathrm{~mm} \times L 120 \mathrm{~mm}$; eluent, $\mathrm{H}_{2} \mathrm{O}$ ) to remove excess $\mathrm{KOH}$.

\section{Interfacial Copolycondensation ${ }^{4}$}

A mixed solution of HDA $(3 \mathrm{mmol})$ and sodium hydroxide $(\mathrm{NaOH})(1.5 \mathrm{mmol})$ in water $(20 \mathrm{ml})$ was poured onto a solution of acid dichlorides $\mathrm{BC}+\mathrm{AC}(3 \mathrm{mmol})$ in the same volume of carbon tetrachloride. The reaction mixture was vigorously stirred using a homogenizer $\left(1 \times 10^{4} \mathrm{rpm}\right)$ for $5 \mathrm{~min}$. The resulting copolyamide was collected, washed with water, and dried at $60^{\circ} \mathrm{C}$ under reduced pressure.

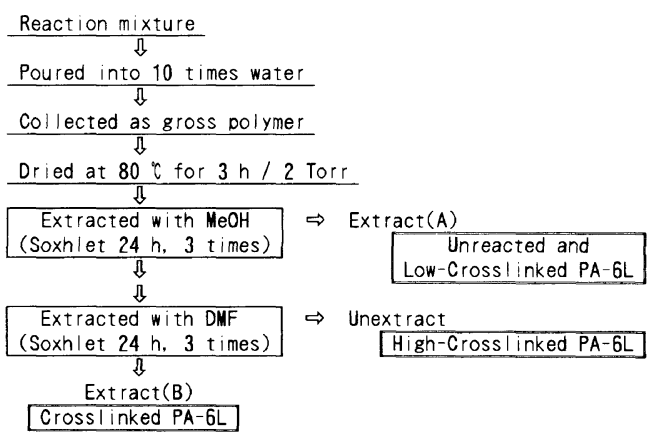

Scheme 1. Separation procedure of the crosslinked PA$6 \mathrm{~L}$. 
Typical Crosslinking of $P A-6 L^{5}$

To a solution of PA-6L $(0.4 \mathrm{~g}, 1.74 \times$ $\left.10^{-2} \mathrm{mmol}\right)$ in DMAc $(10 \mathrm{ml})$, a solution of MDI $\left(0.13 \mathrm{~g}, 5.22 \times 10^{-1} \mathrm{mmol}\right)$ in DMAc $(10 \mathrm{ml})$ and 1,8-diazabicyclo[5.4.0] undec-7-ene (DBU) $(0.05 \mathrm{ml})$ were added, and the reaction mixture was stirred at r.t. for $24 \mathrm{~h}$ under a nitrogen atmosphere. After the reaction, the reaction mixture was treated according to Scheme 1.

\section{RESULTS AND DISCUSSION}

\section{Chemical Treatment of $P A-6 L$}

The original PA-6L was treated with acids and alkalis. The results are summarized in Table I. Chemical treatment of PA-6L was accompanied by increase in the ring-opening ratio and water content. Both values obtained suggest an adequate correlation. On the other hand, $[\eta]$ of PA-6L in methanol decreased by the chemical treatment, except for $0.6 \%$ $\mathrm{KOH}$ aq. The diminution rate is apt to rise with increase in ring-opening ratio. PA-6L modified by $\mathrm{KOH}$ also showed lower $[\eta]$ in formic acid compared with the original one. Besides the hydrolytic cleavage of $\gamma$-lactone ring, therefore, the hydrolytic scission of amide linkage in a main chain seems to caused by chemical treatment.

Typical IR spectra of treated PA-6L samples are illustrated in Figure 1 compared with that of original PA-6L. Common carbonyl absorptions owing to $\gamma$-lactone ring, carboxyl group, and amide linkage appeared at 1780 , 1700,1660 , and $1530 \mathrm{~cm}^{-1}$. In the case of $\mathrm{KOH}$-treatment there appeared a new absorp-

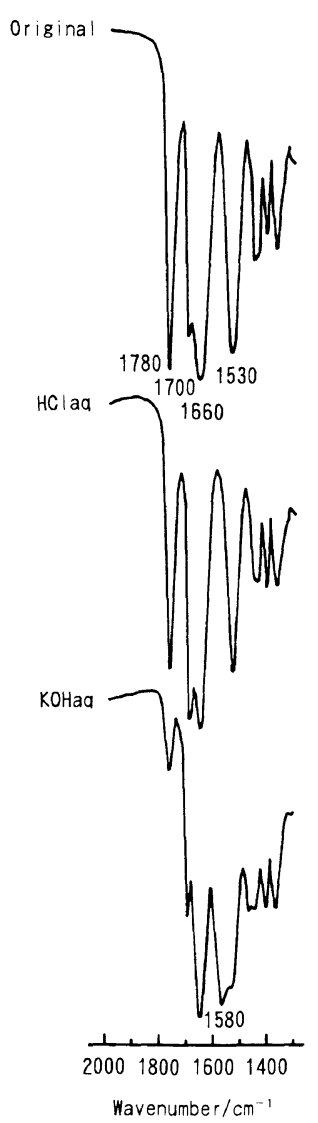

Figure 1. IR spectra of PA-6L modified by chemical treatment.

Table I. Chemical treatment of PA-6L

\begin{tabular}{|c|c|c|c|}
\hline \multirow{2}{*}{$\begin{array}{l}\text { Treatment } \\
\text { agent }\end{array}$} & \multirow{2}{*}{$\begin{array}{l}\text { Ring-opening } \\
\text { ratio }\end{array}$} & \multirow{2}{*}{$\frac{\text { Water content }}{\%}$} & \multirow{2}{*}{$\frac{[\eta]^{\mathrm{a}}}{\mathrm{dl} \mathrm{g}^{-1}}$} \\
\hline & & & \\
\hline Original & 0.36 & 25 & $0.27(0.42)^{\mathrm{b}}$ \\
\hline $90 \% \mathrm{HCOOH} \mathrm{aq}$ & 0.42 & 37 & 0.24 \\
\hline $37 \% \mathrm{HCl} \mathrm{aq}$ & 0.59 & 43 & 0.22 \\
\hline $28 \% \mathrm{NH}_{3} \mathrm{aq}$ & 0.61 & 41 & 0.20 \\
\hline $0.6 \% \mathrm{KOH} \mathrm{aq}$ & 0.75 & 85 & $0.38(0.32)^{b}$ \\
\hline
\end{tabular}

a Measured in $\mathrm{MeOH}$ at $25^{\circ} \mathrm{C}$.

b $90 \% \mathrm{HCOOHaq}$ was used in the place of $\mathrm{MeOH}$. 
tion band at $1580 \mathrm{~cm}^{-1}$ due to $-\mathrm{COO}^{-} \mathrm{K}^{+}$ formed by the hydrolytic cleavage of $\gamma$-lactone ring with $\mathrm{KOH}$. The carboxylato-containing PA-6L was highly soluble in water $\left(25 \mathrm{~g} \mathrm{dl}^{-1}\right.$ at $\left.60^{\circ} \mathrm{C}\right)$. The unusual increase of $[\eta]$ in methanol of $\mathrm{KOH}$-treated PA-6L must be caused by hydration owing to the formation of $-\mathrm{COO}^{-} \mathrm{K}^{+}$group.

\section{Preparation of Copolyamide- 6 L/66}

Copolyamide-6L/66 was prepared by interfacial copolycondensation of acid dichlorides,

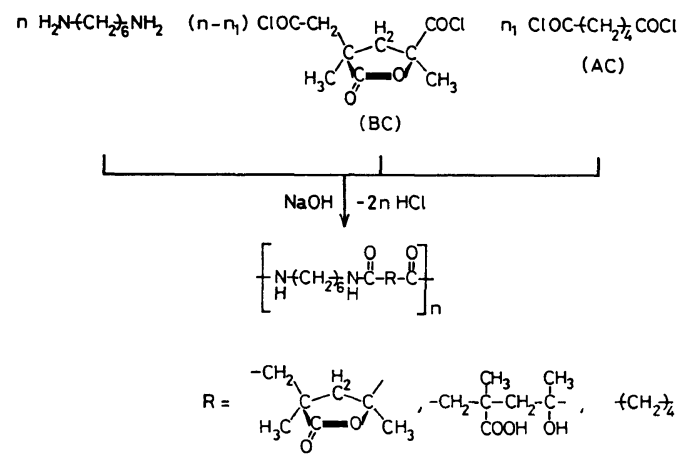

Scheme 2. Preparation of copolyamide-6L/66.

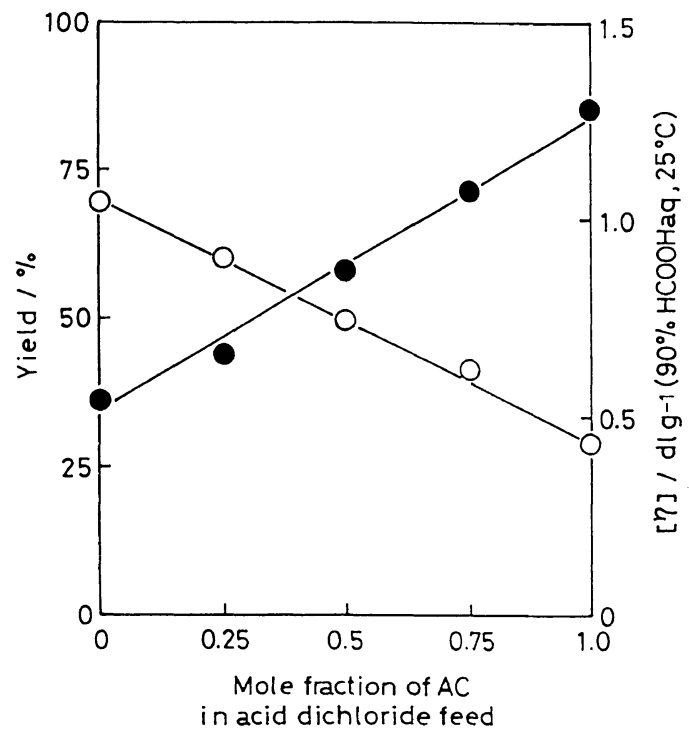

Figure 2. Effect of mole fraction of $\mathrm{AC}$ on yield $(-\mathrm{O}-)$ and intrinsic viscosity (- - ) of copolyamide$6 \mathrm{~L} / 66$.
$\mathrm{BC}$ and $\mathrm{AC}$, with HDA as shown in Scheme 2. As described in the previous paper, ${ }^{1}$ the highest value of $[\eta]$ of PA-6L is achieved at $[\mathrm{BC}]:[\mathrm{HDA}]:[\mathrm{NaOH}]=1: 1: 0.5$, whereas the best yield at a stoichiometric molar ratio, $[\mathrm{BC}]:[\mathrm{HDA}]:[\mathrm{NaOH}]=1: 1: 2$. Therefore, the effect of mole fraction of $[\mathrm{AC}] /([\mathrm{BC}]+$ $[\mathrm{AC}])$ on yield, $[\eta]$ in formic acid, solubility in methanol, and water content of copolyamide-6L/66 was studied under the optimal conditions for preparation of high molecular weight PA-6L. As illustrated in Figure 2, the yield of copolyamide-6L/66 decreased linearly with increase in the mole fraction of $\mathrm{AC}$, while $[\eta]$ increased linearly. This contrasting behavior indicates that the participation of $\mathrm{AC}$ under the unstoichiometric molar ratio, [acid dichlorides]:[HDA] : $[\mathrm{NaOH}]=$ $1: 1: 0.5$ makes a contribution to the preparation of high molecular weight copolyamide$6 \mathrm{~L} / 66$ at the sacrifice of yield. As illustrated in Figure 3, both the solubility in methanol and water content of copolyamide- $6 \mathrm{~L} / 66 \mathrm{de}-$ creased forming a curve with increase in the mole fraction of $\mathrm{AC}$. The resulting co-

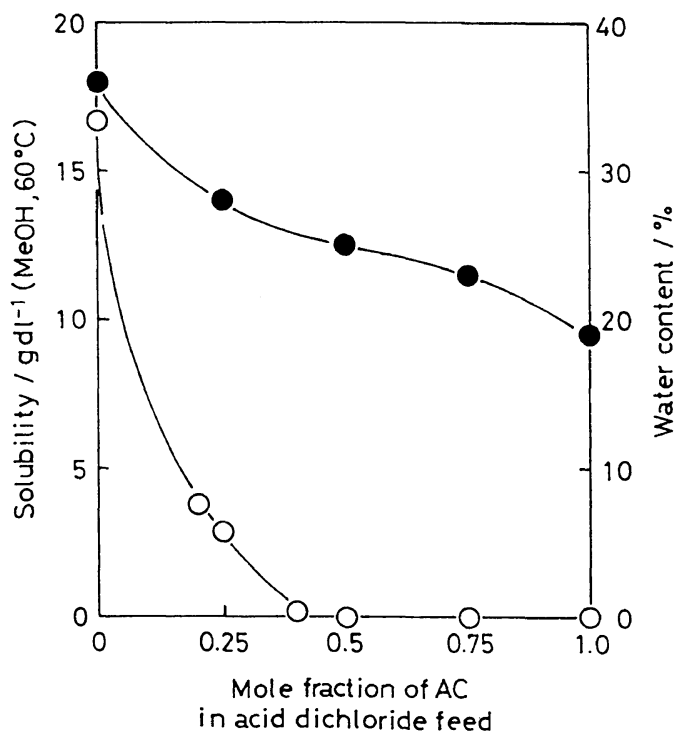

Figure 3. Effect of mole fraction of AC on solubility in $\mathrm{MeOH}(-\mathrm{O}-)$ ) and water content (- - ) of copolyamide- $6 \mathrm{~L} / 66$. 
polyamide-6L/66 was no longer soluble in methanol when the mole fraction of $\mathrm{AC}$ was beyond 0.4 . A methanol-soluble copolyamide$6 \mathrm{~L} / 66$ was prepared at a mole fraction of $\mathrm{AC}$ of $c a .0 .25$.

\section{Synthesis and Characterization of $P A-6 L$} Crosslinked with MDI

As shown in Scheme 3, crosslinked PA-6L was prepared by the addition of PA-6L with MDI in the presence of DBU as a catalyst. Table II shows the conditions for the synthesis of crosslinked PA-6L. After the reaction, the crosslinked PA-6L was separated according to the procedure shown in Scheme 1. The results of the fractionation of crosslinked PA-6L are shown in Table III. The compositions of extracts (A), (B) and unextract are supported by the comparisons of those IR and ${ }^{1} \mathrm{H}$ NMR spectra. The crosslinked PA-6L fractionated as extract (B) is a sample for the following spectroscopic and thermal analyses.

The IR spectrum of PA-6L (CPA-2) crosslinked with MDI is illustrated in Figure 4, and compared with those of original PA-6L and MDI. In addition to the carbonyl absorptions owing to $\gamma$-lactone ring (1780), carboxyl group (1700), and amide linkage (1650 and $\left.1540 \mathrm{~cm}^{-1}\right)$, there appeared new absorption peaks marked $(\boldsymbol{\Delta})$ in Figure 4 at 3320, 1700,1600 , and $1520 \mathrm{~cm}^{-1}$. These absorption

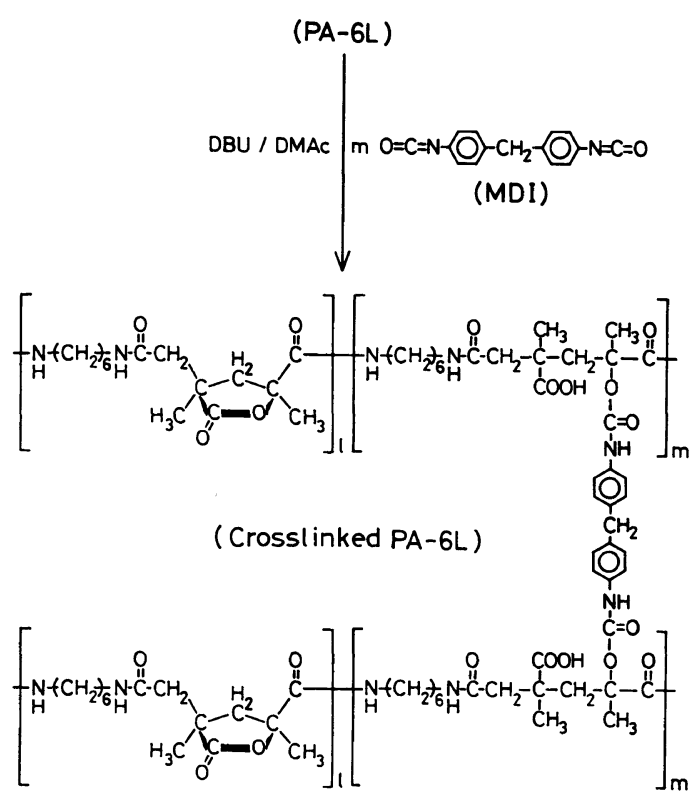

Scheme 3. Preparation of crosslinked PA-6L.

Table II. Crosslinking conditions of PA-6L

\begin{tabular}{|c|c|c|c|c|c|c|}
\hline \multirow{2}{*}{$\begin{array}{l}\text { Sample } \\
\text { code }\end{array}$} & \multicolumn{3}{|c|}{ PA-6L } & \multirow{2}{*}{$\frac{[\mathrm{MDI}]}{[\mathrm{PA}-6 \mathrm{~L}]}$} & \multirow{2}{*}{$\frac{\mathrm{DBU}}{\mathrm{ml}}$} & \multirow{2}{*}{$\frac{\text { DMAc }}{\mathrm{ml}}$} \\
\hline & $\bar{M}_{v} \times 10^{-3}$ & $-\mathrm{OH}^{\mathrm{a}}$ & $\mathrm{g}\left(\mathrm{mmol} \times 10^{2}\right)$ & & & \\
\hline CPA-1 & 3.9 & 7 & $0.35(9)$ & 7 & 0.05 & 20 \\
\hline CPA-2 & 7.0 & 8 & $1.50(21)$ & 8 & 0.15 & 75 \\
\hline CPA-3 & 23.0 & 30 & $0.40(2)$ & 30 & 0.05 & 20 \\
\hline
\end{tabular}

a Average number of $\mathrm{OH}$ group: average degree of polymerization $\times$ ring-opening ratio.

Table III. Fractionation of crosslinked PA-6L

\begin{tabular}{|c|c|c|c|c|}
\hline \multirow{2}{*}{$\begin{array}{l}\text { Sample } \\
\text { code }\end{array}$} & \multirow{2}{*}{$\frac{\text { Yield }^{\mathrm{a}}}{\mathrm{g}}$} & \multicolumn{3}{|c|}{ wt $\%$} \\
\hline & & Extract(A) & Extract(B) & Unextract \\
\hline CPA-1 & 0.34 & 37 & 57 & 6 \\
\hline CPA-2 & 1.19 & 58 & 37 & 5 \\
\hline CPA-3 & 0.39 & 28 & 62 & 10 \\
\hline
\end{tabular}

\footnotetext{
a Weight of gross polymer.
} 


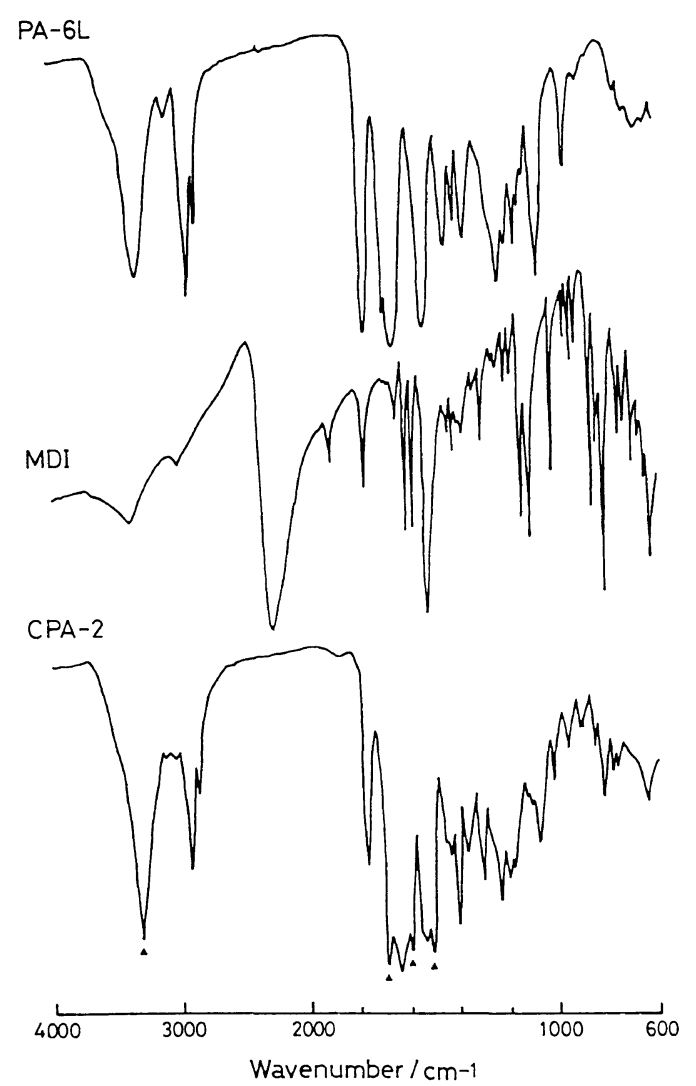

Figure 4. IR spectra of MDI and original crosslinked PA-6Ls.

peaks correspond to the urethane linkage and aromatic ring incorporated by the crosslinking of PA-6L with MDI. Furthermore, the crosslinking of PA-6L seems to be accompanied by a secondary cleavage of the $\gamma$-lactone ring because the carbonyl absorption owing to $\gamma$-lactone ring (1780) is weakening relative to those owing to amide linkage (1650 and $1540 \mathrm{~cm}^{-1}$ ). Elemental analysis of CPA-2 indicated that one molecular unit of PA-6L backbone is crosslinked efficiently by more than eight molecular units of MDI (Found: C, $64.87 \%$; H, $6.92 \%$; N, 10.23\%. Calcd as eight degrees of crosslinking: $\mathrm{C}, 61.32 \%$;, $7.35 \%$; $\mathrm{N}, 9.53 \%$ ). On the reactivity of MDI, it has been reported that the reactivity of the residual isocyanato group falls to one-third after the reaction of one of two isocyanato

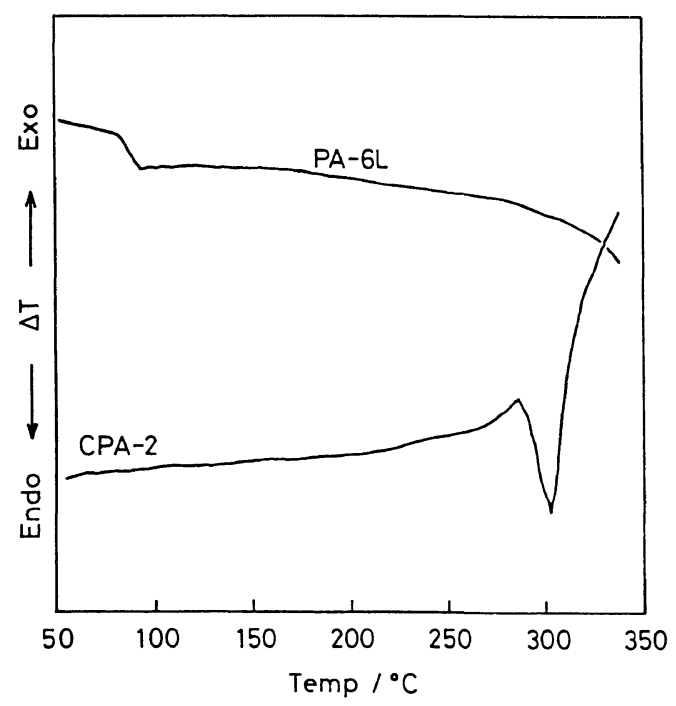

Figure 5. DSC curves of original and crosslinked PA6Ls.

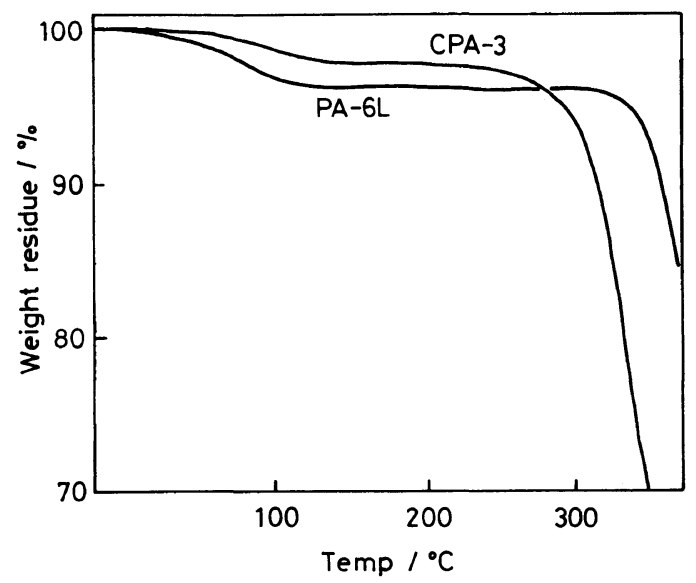

Figure 6. TG curves of original and crosslinked PA$6 \mathrm{Ls}$.

groups. ${ }^{6}$ Therefore, taking into account the discrepancy from the calculated value, it does not necessarily follow that two isocyanato groups of MDI react perfectly with PA-6L. The PA-6L crosslinked with MDI results in a lowering of hydrophilicity (water content, $16 \%$ ), and is characterized by the property of not dissolving in methanol, which is a good solvent for the original PA-6L.

Figure 5 shows the DSC curves of original 
and crosslinked (CPA-2) PA-6L samples. A glass transition temperature $\left(T_{\mathrm{g}}\right)$ is clearly observed at $88^{\circ} \mathrm{C}$ for the original PA-6L. On the other hand, the CPA-2 sample has a sharp endothermic peak at $303^{\circ} \mathrm{C}$ instead of no $T_{\mathrm{g}}$. This point corresponds to the decomposition of crosslinked PA-6L. Figure 6 shows the TG curves of the original and crosslinked (CPA-3) PA-6L samples. The weight loss of both samples at temperature near $100^{\circ} \mathrm{C}$ is presumed due to loss of absorbed water. As the original PA-6L is very hydrophilic, the weight loss of it is larger than that of the crosslinked one. However, the crosslinked PA-6L is accompanied by a precipitous loss of weight when the heating temperature rises to more than $280^{\circ} \mathrm{C}$. Therefore, the thermostability of crosslinked PA-6L is unexpectedly inferior to that of the original one at temperature beyond $280^{\circ} \mathrm{C}$.

\section{CONCLUSION}

The results on modification of PA-6L may be summarized as follows.

1) Adjustment of the ring-opening ratio of PA-6L is possible to a certain extent by treating with either acids or alkalis. However, PA-6L is subject to hydrolytic scission of the amide linkage through this treatment. The water-soluble polyamide can be prepared by treatment with $\mathrm{KOH}$ because of a stable $-\mathrm{COO}^{-} \mathrm{K}^{+}$group.
2) Under optimal conditions for the preparation of high molecular weight PA-6L, the interfacial copolycondensation of acid dichlorides, $\mathrm{BC}$ and $\mathrm{AC}$, with HDA gives a methanol-soluble copolyamide-6L/66 at a mole fraction of $\mathrm{AC}$ of $c a .0 .25$.

3) The weight loss of crosslinked PA-6L proceeds rapidly over $280^{\circ} \mathrm{C}$, and is unexpectedly inferior to the original one in thermostability.

Acknowledgments. The authors thank Mr. Tetsuji Kodaira of GE Plastics Japan Ltd. for the thermal analysis of polymers. We are also grateful to Dr. Motohiro Tsubota and Dr. Kazuo Haga of Utsunomiya University for their helpful discussion.

\section{REFERENCES}

1. T. Kimura, H. Morimoto, E. Sasaki, K. Tanji, and M. Hamashima, Polym. J., 22, 1015 (1990).

2. T. Kimura, K. Tanji, and M. Minabe, Polym. J., 24, 1311 (1992).

3. H. G. Elias and R. Schumacher, Makromol. Chem., 76, 23 (1964).

4. P. W. Morgan and S. L. Kwolek, J. Chem. Ed., 36, 182 (1959).

5. Y. Ikeda, S. Kohjiya, S. Yamashita, N. Yamamoto, K. Hayashi, and I. Yamashita, Nippon Kagaku Kaishi, 699 (1986).

6. J. Burkus and C. F. Eckert, J. Am. Chem. Soc., 80, 5948 (1958). 